\title{
Identidad, oposición y pragmatismo: el contenido de los médios en una elección presidencial
}

\section{Alfredo Ascanio}

\section{(2) OpenEdition}

1 Journals

\section{Edição electrónica}

URL: https://journals.openedition.org/pontourbe/1243

DOI: 10.4000/pontourbe.1243

ISSN: 1981-3341

\section{Editora}

Núcleo de Antropologia Urbana da Universidade de São Paulo

\section{Refêrencia eletrónica}

Alfredo Ascanio, «Identidad, oposición y pragmatismo: el contenido de los médios en una elección presidencial», Ponto Urbe [Online], 1 | 2007, posto online no dia 30 julho 2007, consultado o 28 julho 2022. URL: http://journals.openedition.org/pontourbe/1243; DOI: https://doi.org/10.4000/pontourbe. 1243

Este documento foi criado de forma automática no dia 28 julho 2022.

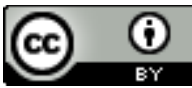

Creative Commons - Atribuição 4.0 Internacional - CC BY 4.0 https://creativecommons.org/licenses/by/4.0/ 


\title{
Identidad, oposición y pragmatismo: el contenido de los médios en una elección presidencial
}

\author{
Alfredo Ascanio
}

\section{NOTA DO AUTOR}

Professor da Universidade Simón Bolívar, Venezuela.

\section{Planteamiento del problema}

1 El objetivo de la investigación consistió en relacionar dos o más variables que pudieron condicionar el comportamiento de los votantes y de la prensa escrita en un contexto de crisis. La pregunta básica a responder fue: $i$ cómo se relacionó la intención del voto de los ciudadanos con la agenda de la prensa escrita en un momento de turbulencia política? La idea fue aportar evidencias empíricas en relación a la llamada teoría de la "Agenda -Setting" y sus efectos en el mundo real de crisis que estaba afectando el voto, para determinar si lo que divulga la prensa escrita sobre los candidatos de una campaña política presidencial tenía o no influencia en la intención del voto del ciudadano; así como evaluar cuáles factores eran realmente los importantes, tanto para el votante como para la prensa escrita en su género de noticias y opiniones, pero en un entorno turbulento.

2 La investigación se justificaba debido a que la teoría de la Agenda -Setting es un sujeto muy debatido y a veces controversial, ya que el valor de los hallazgos pudiesen determinar o no el papel de los medios y la opinión pública, durante una campaña política determinada.

3 La viabilidad de la investigación solamente tenía razón, si se seleccionaban dos periódicos de elevada circulación y considerados como prestigiosos. Analizar el 
universo completo de todas las frases temáticas que se referían a los candidatos que habían polarizado la campaña presidencial de 1.998 , sólo se podía realizar de dos maneras; o el análisis de contenido se realizaba apoyándose en un software específico para esta tarea, o bien realizando un cuidadoso análisis visual y manual, pero con el apoyo de la herramienta Excel, para facilitar el análisis de frecuencias y sus implicaciones. El autor se decidió por el último procedimiento de trabajo, a fin de no perder la visión integral de todos los contenidos.

\section{El marco referencial}

El marco teórico sobre la Agenda-Setting y la intención del voto es muy amplio. Desde los estudios de Walter Lippmann realizado (1.922) para indagar sobre la relación de los medios y la agenda pública, pasando por la función de los medios al configurar sus agendas y los criterios pertinentes con el aporte de Harold Lasswell (1949), Paul F. Lazarsfeld (1962), R,.Merton, Bernard Cohen (1963), Maxwell McCombs (1972), Donal Shaw (1972), Roger Cobb (1972), Ray Funkhouser (1973), Charles Elder (1983), S. Iyenger (1987), Donald Kinder (1987) y Violeta Morin (1974). Todo ello con la idea de investigar tanto los efectos directos sobre el comportamiento de los lectores de la prensa, así como los efectos indirectos que pudiesen reforzar actitudes ya existentes, la influencia de los líderes de opinión y los efectos persuasivos y el encuadre bien sea temático o episódico, a los fines de buscar implicaciones de costos y beneficios; o bien, explicar el por qué, cómo y cuándo ocurre el fenómeno de colocar una agenda en los medios y su posible comportamiento.

5 Como existían piezas de las teorías que permitían hacer generalizaciones empíricas o proposiciones que deberían ser comprobadas o no, el autor al revisar la literatura pertinente, tuvo que centrase en mediciones especificas de determinadas variables muy particulares para el contexto venezolano del momento, a los fines de relacionarlas y estructurar una investigación de tipo explicativa.

\section{Las dos hipótesis principales}

6 Lo que el autor trataba de comprobar lo llevó a las siguientes hipótesis: 1) las decisiones del voto se basan menos en el auto interés de una agenda mediática, pero probablemente mucho más en los comportamientos socio trópicos acerca del bienestar económico individual; y 2) la cobertura episódica de los periódicos se sumaban para vender la noticia como una mercancía.

7 Estas dos proposiciones tentativas que relacionaban la agenda de la prensa, la intención del voto de las personas y el contexto, fueron analizadas en forma sistemática aplicando los índices de desbalance de Harold Lasswell y como unidad de análisis: la frase temática, utilizada por primera vez en la tesis doctoral de Violeta Morin, en la Universidad de Paris.

\section{Introducción}

La elección presidencial del año de 1998 se realizaba en un contexto de crisis política y social. La opinión de John D. Martz (1995) sobre este asunto aseveraba que: 
[...] certainly thr failures of the parties were only a part of the picture. These destabilizing events, largely unanticipated at the outset, reflected prolongad economic decline, unchecked corruption, and concomitant social unrest, all of which alienated ordinary Venezuelans.

9 En efecto, el contrato social entre los partidos políticos y el pueblo se había agotado y estaba dando paso a un nuevo proceso que podía romper la psicología de la alienación. Este proceso se estaba consolidando en un nuevo liderazgo antisistema muchas veces aceptado o bien rechazado e incluso descalificado.

El mismo fenómeno de descentralización y nominalización del voto, había atomizado al futuro votante y había hecho del voto una herramienta de elección bastante volátil, pero un nuevo paradigma ideológico aspiraba aglutinar a los votantes dispersos, aprovechando el desmembramiento de los principales partidos del status. Así, la campaña presidencial de 1998 era un momento propicio para el lanzamiento de nominados independientes, que evitaban identificarse con los partidos tradicionales y que a su vez criticaban duramente lo que se había llamado por años " el pacto de Punto Fijo".

11 La campaña presidencial de 1998 se enmarcó en un contexto no sólo turbulento sino bastante sui generis: partidos tradicionales sin candidatos aceptables y candidatos independientes sin partidos políticos consolidados.

Según un sondeo de opinión realizado por la firma Consultores 21 (1998), los partidos tradicionales venezolanos se habían desacreditado durante las últimas décadas al acentuar el pragmatismo político, pero no así los medios de comunicación de masas los cuales presentaban un adecuado índice de credibilidad, lo cual podía suponer que tendrían una fuerte influencia en la agenda que le trasmitían a un electorado volátil. Se suponía entonces que el poder político del lenguaje de la prensa, en especial la escrita en su género de noticia y opiniones, debería tener alguna influencia en una campaña electoral que se había polarizado en dos candidatos, es decir: Hugo Chávez Frías y Henrique Salas Romer.

13 La prensa escrita, durante la campaña presidencial, trataba de dar significado al debate político al ser selectivos en lo que trasmitía, para intentar configurar y moldear la opinión y si era posible hacer reflexionar a un público votante sobre la conveniencia o no de seleccionar un determinado candidato. Este modo de comunicar buscaba configurar una opinión pública, es decir un producto de opiniones individuales sobre asuntos de interés común de la misma campaña, a los fines de que luego se transformara en un producto colectivo que afectaría a los grupos de interés.

\section{Bases teóricas para el análisis}

14 Siguiendo los conceptos de Julián Cabeza L (1989), la acción de informar y de opinar en la prensa escrita sobre la campaña política presidencial y sobre los dos candidatos y las decisiones de los votantes potenciales, no puede reducirse sólo al comportamiento del emisor y del receptor, cuando uno coloca su agenda y el otro la ha captado, pues este hecho comprende al menos tres aspectos: 1 ) conocimiento de lo que se emite y se capta; 2) comprensión de lo que se emite y se capta; y, 3) aceptación y o rechazo de las noticias o de las opiniones. Durante una campaña política el discurso de la prensa al referirse a los nominados y sus actuaciones, es eminentemente intencional y preformativo, pues es 
un acto de habla, según J.L.Austin, que intenta modificar la percepción de los interlocutores (Ducrot y Tedorov, 1974,pp.384-386).

Igualmente la relación final que los medios de comunicación quieren establecer con sus lectores no es solamente una relación de comunicación, sino también de mercado a través de las noticias y las opiniones y poder de esa manera vender la prensa. No obstante, los medios dejan intencionalmente ciertas huellas o señales que le estarían indicando al receptor sobre el avance o el retroceso de los candidatos competidores, con el fin de inducirlos en su comportamiento como votantes. Es así que las noticias y opiniones resaltaban las características de los personajes que estaban en campaña y resaltaban sus actuaciones, diferenciando los elementos del mensaje y focalizando los comentarios, para señalarle a los receptores la agenda prioritaria de los eventos del día y tratar de influenciarlos en cuanto a la intención del voto.

16 La ideología impregna el campo de la comunicación social y los mensajes expresan el control social a través de la manera como se organizan las frases semánticamente. El mensaje puede ser manifiesto o inferido. El segundo realmente es una meta comunicación que combina signos. Eliseo Verón fue muy claro al señalar (1972) :

[...] en un mensaje el contenido no es lo único que significa, pues cuando digo algo,el modo en que lo digo y lo que no digo y podría haber dicho, son aspectos inseparables de lo que digo.

Tsan-Kuo Chang, et.al., (1992) había señalado que para mucha gente los medios de comunicación son una "ventana al mundo" y una fuente importante de elementos para la formación de la opinión pública y esto fue matizado por Noelle-Neumann (1995), en su espiral del silencio, al señalar que el mundo allí afuera es una realidad, pero que el mundo para la experiencia de mucha gente es solamente un constructo basado en la interpretación de las noticias, es decir: un pseudos mundo subjetivo. Existe pues una construcción social de la realidad a través del proceso de socialización aseverado por Bergan y Luckmann (1966), basado en un "paradigma periodístico" como fue calificado por Joseph Chan y Chin-Chaun Lee, es decir: una manera de seleccionar, interpretar, enfatizar y excluir informaciones y datos, con el fin de mediatizar el mundo de la información (1991).

¿Cuál fue la "visión del mundo" de los que redactaron las noticias o los que opinaron en sus columnas, acerca de la campaña presidencial de 1998 ? ¿Cómo fueron narrados los acontecimientos de la campaña y los señalamientos sobre los candidatos Hugo Chávez y Enrique Salas? . Fue Cohen (1963) quién señaló que el mapa político es diseñado por los reporteros, editores y columnistas y no por cartógrafos. El consumo de determinadas noticias y opiniones por parte de los receptores, generalmente conduce sólo a un conocimiento selectivo acerca de la vida política, pero fue Daniel Yankelovich quien estuvo de acuerdo que estar bien informado nunca es un sustituto satisfactorio de un buen juicio (1991, pp. 5-7).

19 Con todo, ya para el año de 1944 Lazarsfeld, et. al., y Berelson, et. al. para el año de 1954, habían señalado que el rol de los medios consistía en reforzar las convicciones ya existentes y llegaban entonces a la conclusión que su influencia en los receptores era mínima, si se sabe que la mayoría de las personas mantiene una determinada afiliación política , una simpatía y a veces una lealtad a un partido, a un grupo político o a una causa, lo cual condiciona la interpretación selectiva de los mensajes de los medios. Pero es verdad también, como afirmaron Kurt Lang y Gradys Engel Lang, que la cobertura que hacen los medios sirve para dramatizar las campañas políticas desde su 
lado lúdico, como la posible victoria de un candidato, abandonando los aspectos temáticos de fondo: es la narrativa de la campaña como si fuese una "carrera de caballos" (Denham y Millar, on-line).

\section{El marco empírico de la investigación} presidente que los condujera a través de los años y que solucionara muchos problemas acumulados tanto sociales, económicos y políticos. Con el gobierno del Dr. Rafael Caldera estaba terminando su programa de ajustes denominado la Agenda Venezuela, la cual seguía el llamado Consenso de Washington, el cual consistía en fijar metas para restablecer los equilibrios macroeconómicos, abatir la inflación, controlar el gasto público, frenar el déficit fiscal, aumentar las reservas internacionales, obtener un adecuado crecimiento económico y lograr la reforma del Estado, metas todas que no se pudieron alcanzar y que ya formaban parte de la crítica de los nuevos candidatos presidenciales y en especial cuatro de ellos que luchaban por puntear en las encuestas, como Irene Sáez, Hugo Chávez, Claudio Fermín y Henrique Salas Romer.

Al comenzar una contienda electoral siempre nos preguntamos hacia qué destino se comienzan a dirigir las intenciones del voto. Según la encuestadora Compañía Venezolana de Investigación (CVI), los indecisos y los abstencionistas se concentraban en los electores independientes ( $50 \%$ del total), aunque era igualmente significativo que también pertenecían en un $24 \%$ al partido Acción Democrática (AD) y en un $34 \%$ al Partido Social cristiano COPEI. Las organizaciones políticos que tenían apenas un $4 \%$ de abstencionistas eran el Movimiento IRENE y el Movimiento MBR-200.

Durante el comienzo de la pre-campaña, la nominada Irene Sáez estaba ya posesionada en el primer lugar de las encuestas, pero para la primera semana de enero del año 1998 ya había perdido votos y en cambio los nominados Chávez, Salas y Fermín mantenían curvas ascendentes. Los votos para la candidata Sáez eran muy volátiles, pues apenas un $19 \%$ del total eran de personas de su misma agrupación política. Lo mismo sucedía con el candidato Salas Romer, pero no así para el candidato Chávez pues el 25\% pertenecían a su propio movimiento MVR y al partido Patria para Todos y un 59\% de votantes independientes. Gladys Villaroel (1998) había demostrado que la socialización política en Venezuela le indicaba que existía una asociación entre la participación política y los estratos pobres de la sociedad, pero que igualmente los estratos medios educados no les agradaba la participación en política, pues sólo estaban conformes con una valoración normativa de la democracia. Estos últimos eran votantes inseguros y por ello podrían ser más fácilmente arrastrados por los comentarios, las noticias y las opiniones en los medios de comunicación o de familiares y amigos. Incluso el candidato más controversial hacia que los medios y las personas votantes quedaran envueltos en los conflictos que ese candidato divulgaba y en especial si venían acompañados de muchos riesgos para aquellas personas que podían perder sus privilegios. Esto lo afirmó rotundamente Janet Kelly cuando durante la campaña presidencial anotó lo siguiente:

[....] todos los venezolanos están de acuerdo en que el gobierno no funciona y que sus fallas constituye la traba principal para el desarrollo del país; y es que el venezolano abriga más esperanzas con respecto a sus perspectivas que con respecto a las del Estado o el país en general, porque para esas personas los fracasos irrumpen diariamente en la escena pública, pero siempre oyen que se dice que la culpa es del otro, en resumen : nadie cede sus privilegios. 
La campaña en un ambiente maniqueo de confrontación por el poder, hacia que unos candidatos protegieran sus fueros y sus convicciones para imponer sus aseveraciones y los otros defendieran las actuaciones de sus adherentes. El clima de rivalidad y de hostigamiento fue un rasgo sorprendente en esta campaña política.

\section{La metodología utilizada en el trabajo}

24 El autor fundamentó su investigación en la teoría de la agenda setting, a fin determinar quién y cómo se estaba manejando el proceso de la formación de la opinión pública , si eran los medios que podían tener influencia sobre los votantes o eran los votantes quienes evaluando sus experiencias, en un contexto turbulento, conformaban su propia agenda al seguir los llamados del candidato mesiánico.

La agenda de los votantes aparecía en todas las encuestas profesionales que se publicaban en la prensa escrita y la agenda de los periódicos se reflejaba en las frecuencias de lo que se decía sobre cada candidato y sus actuaciones. Fue necesario entonces analizar, durante 11 meses, más de 1.336 frases temáticas (durante la precampaña 845 frases), las cuales censuraban o bien aplaudían a determinados nominados en dos periódicos de elevada circulación y de prestigio como El Nacional y El Universal, dedicados a cubrir las noticias o bien las opiniones acerca de los dos candidatos, que ya habían polarizado la campaña presidencial de 1998, es decir el candidato Chávez y el candidato Salas.

Los mensajes manifiestos rescatados de los dos periódicos dieron origen a series de frecuencias para un conjunto de categorías y estos datos fueron examinados aplicando los índices de desbalance de Lasswell, como lo había plateado Violeta Morin en su tesis doctoral Tratamiento periodístico de la información (1974).

27 Los seis índices de Harold Lasswell, elaborados con la colaboración de Irving Janis y Raymond Fadner, eran los siguientes: 1) el índice de frecuencia de las frases temáticas y de una categoría en un grupo, es el porcentaje de repetición o grado de verbalismo; 2) el índice de politización absoluto y ponderado de una categoría, independiente de su grupo, es el porcentaje de frases temáticas orientadas bien sea hacia lo positivo o hacia lo negativo, reflejando así el grado de pasión política en el discurso; 3) el índice de orientación absoluto y ponderado de una categoría, independiente de su grupo, es el porcentaje de frases temáticas que dominaban positiva o negativamente, reflejando el grado de convicción puesto en esa orientación; 4) el índice de compromiso es el grado de orientación ponderado, según el número de frases temáticas positivas o negativas en relación a sus totales, lo cual indicaba el grado de dogmatismo para defender una orientación determinada en relación a las otras categorías.

Las 845 frases temáticas, durante la pre-campaña, sobre los candidatos y sus actuaciones, que aparecieron en los dos diarios analizados (una encuesta no reactiva sobre lo divulgado en la prensa escrita), dieron origen a frases altamente verbalizadas o no, frases con una elevada o no pasión política, frases con una elevada o no convicción política y frases altamente o no dogmatizadas. Esta narrativa, adecuadamente tabulada y analizada, estaría señalando el apoyo o bien el rechazo de la prensa escrita a los candidatos que habían polarizado en la campaña presidencial.

En resumen: en esa narrativa de los diarios se estaba también votando por un determinado candidato y ese voto de la prensa escrita se comparaba con la intención 
del voto de los personas y con un índice de turbulencia social, a los fines de buscar asociaciones estadísticas bien sea con el análisis de correlación de Pearson y el Tau de Kendall o bien con la correlación por rango (Rho de Speraman) entre el apoyo de los medios y el apoyo de los electores, utilizándose igualmente el test chi-cuadrado para conocer el significado de esos votos favorables.

\section{Los hallazgos de la investigación} La imagen de los dos periódicos analizados sobre el candidato Chávez estaba señalando que durante 23 semanas se oscilaba entre las valencias positivas que correspondían a la aceptación del candidato y las valencias negativas que correspondían a su rechazo, una curva oscilante con picos de aceptación y picos de rechazo, lo cual nos indicaba que estamos en presencia de un discurso suma cero; una manera casi diplomática de no tomar ninguna posición. Incluso cuando repuntaba la intención del voto de los ciudadanos, que siempre se incrementaba mes a mes, entonces los diarios comenzaban a divulgar frecuencias negativas, especialmente desde el mes de abril al mes de julio, lo cual se podía calificar de una especie de "guerra sucia", estrategia que se había transformado en un "boomerang", ratificado por el periodista Héctor Landaeta, cuando señaló, en la separata especial del Diario El Globo, lo siguiente:

[...] pareciera que en estas primeras de cambio el antichavismo se está convirtiendo en un boomerang, pues cada vez que atacan a Chávez,su candidatura sube. Hay una lógica elemental que opera en el venezolano común: si quienes atacan a este candidato son los políticos tradicionales, quienes lo señalan como una especie de diablo, entonces ese pueblo decepcionado del liderazgo tradicional por deducción llega al convencimiento de que si los malos atacan a Chávez es porque este es bueno.

La imagen del candidato Salas en los diarios analizados y durante las 23 semanas siempre fue positiva pero descendente, pues los diarios al final de la pre-campaña casi no le dieron cobertura y por el contrario le restaron respaldo; en efecto, desde el mes 
de marzo y hasta el mes de julio casi desaparecen las noticias y opiniones sobre este nominado, pues seguramente la prensa se concentraba en divulgar, para bien o para mal, lo que estaba sucediendo con el candidato Chávez, el cual se había ya transformado en el candidato mediático que asegura una mejor venta de la prensa escrita.

Las noticia y las opiniones sobre la campaña se transformaron en un espectáculo y se abandonaron los aspectos sustantivos del debate. El mensaje periodístico revelaba que existía mayor complacencia con actitudes y valores superficiales que no correspondían al nivel político-cultural de los venezolanos. Hubo un vacío para divulgar argumentos esenciales, por lo que la prensa no logró realmente guiar en forma eficaz el desarrollo de la campaña presidencial.

La asociación entre apoyos y rechazos tanto de los medios como de los electores fueron comparados para calcular una correlación por rango (Rho de Spearman) tanto para el nominado Salas como para el nominado Chávez.

La correlación o asociación fue negativa en 0,30 para Salas, es decir que no había coincidencia entre las series de datos recogidos de los medios y de las encuestas sobre la intención de votos del electorado. Esta asociación negativa fue mayor en el caso del candidato Chávez, es decir 0,50 . Incluso al aplicarse una regresión múltiple entre las variables independientes: agenda de los medios e índice de severidad social ponderado, con la intención del voto como variable dependiente, aparecieron correlaciones negativas entre el apoyo de los electores y el apoyo de los medios, pues esos apoyos seguían caminos distintos, siendo estadísticamente significativos.

El apoyo por parte de los diarios siempre fue mayor para el nominado Salas en relación al nominado Chávez. Pero mientras los periódicos, al final de la pre-campaña y durante la campaña, no privilegian a los candidatos, los electores si les concedían su apoyo. Aparentemente, la influencia de los medios sobre el electorado no fue tan evidente en este contexto de crisis. Pero la poca influencia de los medios, de una manera inversa al comportamiento de los electores, fue solamente una parte de las posibles variables que influyeron en la campaña presidencial de 1998. Las otras variables relacionadas con el contexto, fueron las siguientes: la turbulencia política, la volatilidad de la intención del voto, la influencia de las comunicaciones interpersonales, el carisma de los candidatos, las motivaciones del elector, el perfil ideológico del electorado y su participación política, todo lo cual podría asegurar una posible hipótesis de la economía del voto o quizá del llamado voto castigo, muy relacionados con las teoría sociológica denominada de la acción orientada, una forma, utilizada por el votante, para buscar motivos y tomar un curso de acción hacia un objetivo, a fin de superar un posible malestar acumulado.

\section{Conclusiones y discusión}

La investigación sobre los comportamientos de la prensa escrita y la elección presidencial venezolana del año 1998 se enmarcó dentro de la teoría de la agendasetting y de la noticia como espectáculo. Los medios, en este caso los periódicos analizados, controlaban la selección de los temas políticos para su cobertura predominante, pero también los llamados pseudoeventos con un mayor contenido lúdico.

40 La ocasión elegida para realizar la investigación fue la elección presidencial celebrada en Venezuela con una pre-campaña de enero al mes de agosto y de agosto hasta el mes 
de diciembre, la campaña propiamente dicha. La investigación duró 11 meses y se trabajó con el universo total de frases temáticas que se referían al los candidatos nominados Chávez y Salas y sus actuaciones, tanto en el género de noticias como en el género de opinión. Se analizaron 1.336 frases temáticas tomadas de los diarios El Nacional y El Universal.

La unidad de análisis para tabular los contenidos fue la frase temática, es decir una frase que aunque cambie el predicado, siempre se puede encontrar en ella un tópico o una unidad de significado. Es aquella frase que aunque cambie lo que se dice del sujeto siempre estaría señalando que se otorga o una valencia positiva (+), cuando la frase anima o "aplaude" la presencia del candidato y sus actuaciones; o bien, que se otorga una valencia negativa (-) cuando la frase no acepta al candidato y sus actuaciones, ya sea haciendo irreductible la oposición política, ya sea transformando la mesura en una agresividad. Entre estas dos posiciones no se vislumbraba ningún matiz intermedio, sólo una frase temática neutra que sirve de grado límite o grado cero de intensidad.

En esta investigación se tabularon todas las frases temáticas que se referían a los candidatos Chávez y Salas, desde el primero de enero hasta el cuatro de diciembre del año 1.998. Durante el mes de enero destacaron claramente tres temas : apoyo, candidato crece y autocracia (66\% del total de frecuencias analizadas). Pero ya para el mes de julio los temas se habían reducido sólo a: candidato Chávez y rechazo Chávez, otorgándole a estas categorías el $79 \%$ de todos los tópicos tratados y casi había desaparecido la cobertura de prensa para el candidato Salas.

Los diarios privilegiaron la cobertura lúdica de la campaña presidencial, como si estuviesen narrando una "carrera de caballos", abandonando los aspectos sustantivos de la contienda. Las noticias vaciaron de contenido a la precampaña y a la campaña presidencial y al candidato Chávez se le apoyó y se rechazó colocando en la agenda un discurso suma cero (igual los apoyos que los rechazos).

44 En el caso del candidato Salas siempre se le apoyaba, pero ese apoyo fue perdiendo fuerza hasta que se debilitó su cobertura de prensa y casi desaparece, frente a un cobertura del $83 \%$ para el candidato Chávez entre los meses de enero y agosto de 1.998.

La agenda publicada sobre el candidato antisistema Chávez, se había transformado en una agenda publica, mientras la intención del voto, según las encuestas que aparecieron en los diarios por la Compañía Venezolana de Investigación, Mercanálisis, Datanálisis, Consultores 21 y Cosar Grupo, indicaban que el electorado le otorgaba más apoyo al candidato Chávez que al candidato Salas. Las fluctuaciones de la cobertura de los medios no cambió el comportamiento de los votantes, que en un entorno turbulento decidieron apoyar al llamado Polo Patriótico, con un 56,75\% de los votos totales.

Un análisis agudo del periodista Roberto Guisti señaló durante los primeros días del mes de diciembre, lo siguiente:

[....] en este enredo descomunal de tarjetas confiscadas, de candidatos que ya no son, o lo son a medias, es muy difícil precisar cuál será la reacción de los electores. ¿Habrá transferencia automática de los votos que obtuvieron AD y COPEI el 8 de noviembre a la candidatura de Salas? ¿Se irán, por el contrario, los adecos hacia Chávez ante el espectáculo de los partidos tradicionales cuyas cúpulas sólo entendieron lo que estaba pasando cuando se vieron en terapia intensiva o tendrán en cuenta lo de las cabezas en aceite a pesar de sus últimos y fraternales llamados a las bases? 
Durante la precampaña 70 personas, entre reporteros y comentaristas, habían cubierto las noticias y opiniones acerca de este importante evento político, pero realmente apenas el $10 \%$ de los que le dieron cobertura a la campaña colocaron en la prensa más del $50 \%$ del total de las frecuencias analizadas en esta tesis, es decir un a concentración importante de las fuentes.

\section{BIBLIOGRAFIA}

Ascanio, Alfredo (1997). Democracia populista: libertad e igualdad en abstracto, ¿para qué?, Cuestiones Políticas, Maracaibo, Venezuela.

Bryant, Jennings y Zillmann Dolf (1996). Los efectos de los medios de comunicación : investigaciones y teorías, Barcelona, Editorial Paidós.

Cabeza, L. Julián. (1989). Publicidad y discurso, Maracaibo, Universidad del Zulia, facultad Experimental de Ciencias.

Cohen, B. C. (1963). The press and foreign policy, Princeton, N.J. Prtinceton University Press. Chan, Joseph and Lee, Chin-Chaun. (1991). Mas Media and potical transition. The Hong Kong Press in China's orbit, New Cork, The Guilford Press.

Chang, Tsan-Kuo, et. al. (1992). The world as subjetive reality: US newspaper editors'view and its determinants, World Association for Public Opinión Research.

Chimombo, Moira. (1999). Language and politics, Annual Review of Applied Linguistics, 19, 215-232.

Dearing, James and Rogers, Everett. (1996). Agenda-Setting, Thousand Oaks, Sage Publications. Ducrot. Oswaldo y Todorov, Tzvetan. (1974). Diccionario Enciclopédico de las Ciencias Sociales, Madrid, Siglo Veintiuno Editores.

Denham, Bryan y Millar, Mark. (1999). Public Opinión poll during the 1988 and 1992 oresidential election campaigns: an análisis of horserace and isuee coverage in prestige newspapers, http:// excellent.com.utk.edu/.On-line. Internet.

Edelman, M. (1988). Constructing the political spectacle, Chicago, The University of Chicago Press. Landaeta, Héctor (1998). Análisis electoral. El Globo, Separata de la Edición Especial.

Kelly, Janet (1995). Salida, voz y lealtad. El Nacional.

Koeneke R., Herbert. (1999). El enmarcamiento (framing) o grupo céntrico en la campaña electoral venezolana de 1998, Caracas, Universidad Simón Bolívar.

Kraus, Sydney y Davis, Dennos. (1991). Comunicación masiva: sus efectos en el comportamiento político, México, Editorial Trillas.

Lasswell, Harold, et. al. (1949). Language of politics: studies in quantitative semantics, Cambridge, The MIT Press. 
Lazarsfeld, Paul, et. al. (1962). El pueblo elige: estudio del porceso de formación del voto durante una campaña presidencial, Buenos Aires, Imprenta López.

Lippmann W. Public Opinión, (1922), citado por Edelman M. (1988). Constructing the political spectacle, Chicago, The University of Chicago Press.

Morin, Violeta. (1974).Tratamiento periodístico de la información, Barcelona, Mounton y ATE.

Noelle-Neumann, Elizabeth. (1995). La espiral del silencio: nuestra piel social, Barcelona, Editorial Paidós.

Price, Vincent. (1994).La opinión pública: esfera pública y comunicación, Barcelona, Ediciones Paidós.

Van Dijk, T. (1980). Texto y contexto, Madrid, Ediciones Cátedra.

Verón, Eliseo. (1972). Conducta, estructura y comunicación, Buenos Aires, Editorial Tiempos Contemporáneo.

Villarroel, Gladys. (1998). De tal palo tal astilla: patrones de socialización política en Venezuela, Revista Interamericana de Psicología, Vol. 32, No. 1, pp. 1-8.

Wanta, Wayne and Wei-Hu, Yu. (1998). The agenda-setting: effects of internacional news coverage an examination of differing news frames, Internacional Journal of Public Opinión Research, Vol. 5, No. 3, pp - 250-264.

Welsch, Friedrich, et. al. (1983). El mensaje oculto del debate, Cumaná, Editorial La Región. Yankelovich, Daniel. (1991). Coming to public judgment: making democracy work in a complex WWorld, Syracuse, New Cork, Syracuse University Press.

\section{AUTOR}

ALFREDO ASCANIO

Professor da Universidade Simón Bolívar, Venezuela. 